\title{
FPETOOL User's Guide
}

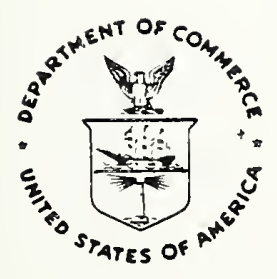

Ú.S. Department of Commerce

National Institute of Standards and Technology

Center for Fire Research

Gaithersburg, MD 20899

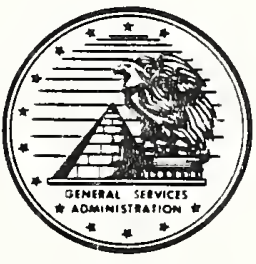

Prepared for:

General Services Administration

Public Buildings Service

Office of Real Property Management and Safety Washington, DC 20405 



\section{FPETOOL User's Guide}

Harold E. Nelson

Contract No. GSA/PBS-87-03

October 1990

U.S. Department of Commerce

Robert A. Mosbacher, Secretary

National Institute of Standards and Technology

John W. Lyons, Director

Center for Fire Research

Gaithersburg, MD 20899
Prepared for:

General Services Administration

Richard G. Austin, Administrator

Public Buildings Service

William C. Coleman, Commissioner

Office of Real Property Management and Safety

Washington, DC 20405 



\section{Users' guide}

\section{Contents}

1. Introduction.

a. Computer Requirements. 1

b. Installation. 1

c. Operating Approach Used in FPETOOL. 2

d. Use of Menus. 3

e. Information Regarding User Entries and Other Action Required to Run FPETOOL. 5

f. Precision Required in Making Entries in FPETOOL 5

g. SYSTEM SETUP 5

h. Additional Guides for Individual Routines 7

2. FIREFORM 7

a. ASETBX ROOM FIRE MODEL 8

b. ATRIUM SMOKE TEMPERATURE. 9

c. BUOYANT GAS HEAD. 9

d. CEILING JET TEMPERATURE. 9

e. CEILING PLUME TEMPERATURE. 10

$\begin{array}{ll}\text { f. } & 10\end{array}$

g. FIRE/WIND/STACK FORCES ON A DOOR. 12

h. MASS FLOW THROUGH A VENT. 12

i. LATERAL FLAME SPREAD. 13

j. LAW'S SEVERITY CORRELATION. 14

k. PLUME FILLING RATE. 14

1. RADIANT IGNITION OF A NEAR FUEL. 14

m. SMOKE FLOW THROUGH OPENING. 15

n. SPRINKLER/DETECTOR RESPONSE. 15

o. THOMAS' FLASHOVER CORRELATION. 16

p. UPPER LAYER TEMPERATURE. 16

q. VENTILATION LIMIT. 18

3. MAKEFIRE 18

a. FORMULA. 18

b. FREEBURN. 18

c. MYFIRE. 19

d. LOOK-EDIT 19

4. FIRE SIMULATOR. 19

a. FIRE SIMULATOR 19

(1) CREATE/REVISE CASE 19

(2) RUN EXISTING CASE 19

(3) ASCII FILE 20

(4) LINING MATERIALS 23

(5) HAZARD WARNINGS 23

b. Creating a new FIRE SIMULATOR case. 23

(1) DEFAULT VALUE - HEAT OF COMBUSTION. 24

(2) DEFAULT VALUE - CRITERIA FOR ASSUMING FLASHOVER. 24

(3) DEFAULT VALUE - OXYGEN STARVATION
CRITERIA.

(4) DEFAULT VALUES - CARBON MONOXIDE/CARBON
DIOXIDE RATIO. 
(5) DEFAULT VALUES - HEAT TRANSFER FACTORS . 26

(6) OPEN DOOR, WINDOW, OR OTHER OPENING. 26

(7) SPACE DIMENSIONS. 27

(8) HEAT RELEASE DATA. 27

(9) HALTING THE PROGRAM. 28

(10) DATA FILE NAME 28

c. RECAPITULATION SCREEN. 28

d. REVISING A FILE. 28

e. Running a FIRE SIMULATOR case. 29

f. Running FIRE SIMULATOR after flashover. 30

g. FAILURE TO CONVERGE. 31

REFERENCES $\quad 32$ 


\author{
FPETOOL User's Guide \\ Harold E. Nelson \\ Center for Fire Research \\ National Institute of Standards and Technology \\ Gaithersburg, MD, 20899 \\ USA
}

\title{
Abstract
}

FPETOOL is a computerized package of relatively simple engineering equations and models. FPETOOL consists of a package of engineering tools useful in estimating potential fire hazard and the response of the space and fire protection systems to the developing hazard. To a large extent user instructions are included as screen messages presented at the time of need by FPETOOL. This document covers information useful to the user, but not included as screen messages.

1. Introduction.

a. Computer Requirements.

FPETOOL is a menu driven, computerized package of relatively simple engineering equations and models.

FPETOOL is programed to operate on computers having MSDOS 3.1 or higher operating systems. A computer having 640 kilobytes of memory is needed. FPETOOL is designed to operate whether or not a math coprocessor is present but operates much faster if a coprocessor is present. It is provided in a condensed format on three double density (360 kilobytes) floppy disks or one high density ( 1.2 megabyte) floppy disks. The disks contain compiled, executable files; text files and a README file. The executable files contain all of the various routines for FPETOOL. The README file provides introductory information. The text files contain a copy of chapters 1 through 5 of this report, this user's guide and the history of revisions to FPETOOL.

FPETOOL requires a hard disk. The minimum disk space needed is over 1.2 megabytes. Since the FIRE SIMULATOR portion of FPETOOL and the MAKEFIRE routines produce files, a minimum of 2 megabytes is suggested. FPETOOL cannot operate successfully on computers without hard disks. However, many of the individual routines in FIREFORM and MAKEFIRE are available on a separate single floppy disk and can be operated without the hard disk. The computer programs are available to the public on the Center for Fire Research Computer

Bulletin Board System (CFRBBS.) Appendix B provides information on using this free public access fire safety resource.

b. Installation.

To install FPETOOL first create a directory. The directory may have any name, but FPETOOL is suggested. Set the prompt on that directory. Then insert the 
provided disks (Start with disk \#1 if the double density disk set is being used), type A:INSTALL and press the ENTER key to load FPETOOL. FPETOOL is now ready for use. Type FPETOOL and press the ENTER key to run FPETOOL. FPETOOL contains many internal guides, frequent messages will appear on the screen to assist the user. It can be operated without using this guide, however, the guide provides additional information that may assist many users.

For those not familiar with installing programs in a computer, the following details the actions to accomplish the above on a typical IBM compatible computer with a hard disk.

(1) Turn computer on. After initial checking, the lowest line on the screen will read:

$$
\mathrm{C}:>
$$

The symbol $C:>$ is called the DOS system prompt. Some versions of DOS produce slightly different appearing prompts.

(2) Type MD $\backslash F P E T O O L$, then press the ENTER key.

(3) Type CD\FPETOOL, Then press the ENTER key.

(4) Insert FPETOOL floppy disk No.1 in drive A, close the latch or lever on the drive A slot.

NOTE: If the drive used for the floppy disk is other than drive A, then replace the letter $A$ in the following command with the letter designation of the drive used.

(5) Type A:INSTALL and press the ENTER key. This will load and de-compress the entire set of files for FPETOOL. If the double density set of three floppy disks is used, the computer will show the message "Next disk" on the computer screen. At this point remove the disk presently in the drive slot and insert the next disk (in number order) and press ENTER.

(6) Type FPETOOL and press ENTER to run FPETOOL.

(7) To return to FPETOOL after the computer has been shut down or the user has left the FPETOOL directory:

(a) Type CD\FPETOOL and press the ENTER key.

(b) Then type FPETOOL and press the ENTER key.

(c) The title screen of FPETOOL will appear, press any key to advance to the Main menu.

c. Operating Approach Used in FPETOOL.

FPETOOL operates from a series of menus. Two types of menus are used. These are: 
(1) Main menu. The main menu defines the structure of FPETOOL. The items in the main menu provide access to other sections of the program. By selecting appropriate item on this menu, you will arrive at the section of FPETOOL that meets your needs.

(2) Data entry menus. Data entry menus provide the means for you to specify the data and other information needed to run the individual routines in FPETOOL.

d. Use of Menus.

To start the program, turn on your computer and call up the directory containing FPETOOL. Type FPETOOL and press the ENTER key, a title screen will appear. Press any key to advance to the Main menu. To select an item on the Main menu, use the right and left or up and down arrow keys to position the selection bar on the screen on the item desired. Then press ENTER. This will bring up on the screen a data entry menu that will call for information of the following types.

(1) Data Entry Items. Numerical values required by the routine being executed.

(2) Toggle Switches. Points that allow the user to select one of a set of values for a program variable (usually ON or OFF).

(3) Sub-Menus. These are menus of related data presented as a separate data (and or toggle switch) entry menu. Some sub-menus contain both data entry and one or more toggle switches.

A data entry item appears on a menu as a description of that item and the dimensions of the value to be entered followed by the current value of that item. (In the case where the value has not yet been provided, the value appears either as a default value preset by the program but changeable by the user or a diamond character indicating that this item requires the user to put in a value in order for the routine to run.) Data is entered into a data entry item by positioning the highlight bar over that item and then typing the value for that item and pressing the ENTER key. As the number is being typed, a box will appear around it. The box will expand as digits are added to the number. When the ENTER key is pressed, the number will then be listed as part of the menu.

A toggle switch item will appear as the current state of the switch followed by a message indicated other possible states for that switch. For example, the most common toggle switch in FPETOOL is the printer status switch which indicates whether the screen output will be sent to the printer or not. The default setting for this switch is "DISABLED" meaning that output is not sent to the printer. In the disabled state, the menu item reads:

PRINTER DISABLED (Press ENTER to enable) 
Pressing the ENTER key will "toggle" the state of the switch changing its state to ENABLED and the menu item will then read:

\section{PRINTER ENABLED (Press ENTER to disable)}

NOTE: If the computer does not find an operating printer on the line the following message will appear: "IF THIS MESSAGE STAYS ON THE SCREEN, THEN FOR SOME REASON THE PRINTER IS NOT ON LINE. PLEASE CHECK THE PRINTER, ITS CABLES, AND CONNECTIONS." If a printer is promptly brought on line the message will disappear and the printer will be "ENABLED." If not a second message will appear reading "DO YOU WANT TO MAKE ANOTHER ATTEMPT TO BRING IT ON LINE? ( $\mathrm{Y} / \mathrm{N}$ )." If the answer is $Y$ FPETOOL will try again to find an on line printer. If the answer is $\mathrm{N}$ the program will proceed with the printer "DISABLED."

Pressing the ENTER key, again will return the switch to the DISABLED state. Other toggle switches work in a similar manner.

A sub-menu will appear as a description of the type of data contained in that sub-menu. The entry item for sub-menus does not include the indication of a dimension. Positioning the highlight bar over the title of the sub-menu and pressing the ENTER key will cause the current menu to be replaced by the submenu. The form and format of the individual sub-menus vary but provide built in instructions to guide the user. When all of the items in the sub-menu have been set and the user is satisfied with them, he selects the item marked "DONE", "FINISHED WITH...", or variations thereof and presses the ENTER key. The program will then return to the menu from which the sub-menu was called.

At various points in the program, the user is asked to make decisions or provide information. At these points, the user is "prompted" for the required response. The program will halt and a description of the requested information will be printed on the screen. At these points, the responses are of two types: data values and decisions. Data values consist of values required for variables in the program or in some cases a descriptive title or statement. To enter a data value, type the digits or text. Use the BACXSPACE key to erase any mistyped characters. When the entry is finished to the user's satisfaction, press the ENTER key. Decisions consist of either Yes or No responses or the selection of one of several options. A Yes or No prompt will be identified by the character "(Y/N)" at the end of the prompt. To answer, press the " $N$ " key to indicate no or any other key to indicate yes. Decisions that require something else besides a yes or no answer are presented as a list of options associated with a single digit number or letter. To select an option, press the key corresponding to the letter or number of your selection. In either case, yes/no, or option, PRESSING THE ENTER KEY IS NOT NEEDED.

At most points in FPETOOL where a response is allowed, the user may choose to abort the normal sequence of the program and either return to the main FPETOOL or abort the program entirely and return to the computer system (DOS prompt). 
Aborting the program is done by entering, instead of the requested information, a control $Q\left({ }^{\wedge} Q\right)$ character. This is done by holding down the key marked "Ctrl" (the CONTROL key) and pressing the key marked $Q$.

e. Information Regarding User Entries and Other Action Required to Run FPETOOL.

An attempt has been made to provide most of the information that the user needs to operate FPETOOL on the screen when the user needs it. In addition, the package contains this user's guide and Chapters 1 through 5 of this report. The following is additional information that attempts to expand and provide guidance to the user.

\section{f. Precision Required in Making Entries in FPETOOL}

The user is advised that the routines and models in FPETOOL are designed to give reasonable approximations but not exact answers. Correspondingly, the user should attempt to describe the situation as it actually exists or is envisioned. Absolute accuracy is not necessarily required, however, users should avoid the types of deviations that become additive.

\section{g. SYSTEM SETUP}

The main menu in FPETOOL contains the item SYSTEM SETUP. The SYSTEM SETUP menu is designed as a convenience for those who make regular use of FPETOOL. FPETOOL can operate successfully without use of SYSTEM SETUP.

The purpose of the SYSTEM SETUP is to allow the user to establish case files. Case files store information that tells FPETOOL where (on what disk or in what directory) to look for input files and where to store output files created by FPETOOL routines. If no adjustments are made, all of the files will be saved on the disk and in the directory used to operate FPETOOL. Users may want to set up case files based on individual user, the name or number of a building, a date or any other convenient identification. When such is done, the files related to an individual case will be stored separately and called separately from that point of storage. When the case file is established, this will be done automatically, inside FPETOOL. In naming case files, the usual rules for naming MSDOS files apply. A case file can have any name consisting of eight or less characters provided the first character is a letter. FIRE SIMULATOR will add the extension ".FPE" to any case file name established.

Once case files have been established, they can be called up from the SYSTEM SETUP menu or can be included in the initial call for FPETOOL. To do the latter, type as two words separated by a space, FPETOOL and the case file path and name. Do not include the .FPE extension. 
(i) The first entry in the SYSTEM SETUP menu is LOAD/SAVE A CASE FILE SET. This provides the user the opportunity to either retrieve a previously developed case file or to save one that he has established with the subsequent commands in SYSTEM. If the user presses the enter key while the highlight bar is on this command, he will be prompted with the question, "DO YOU WANT TO SAVE THE CURRENT CASE AS A FILE ( $Y / N)$ ?" Answer yes to save the current case. If yes is entered, the system will prompt the user to give the case a name. Any file given the name "case," will be called as the default case by FPETOOL any time FPETOOL is entered without indicating a special case. The user is not bound to the default case previously in the file.

(ii) To load a new case, answer no to the previous question. The FPETOOL will prompt "DO YOU WANT TO LOAD A NEW CASE FILE (Y/N)?" Type yes to call up the list of previously developed cases available. Use the cursor to move the highlight bar to the case desired and press the enter key.

Pressing the enter bar brings up the submenu entitled PATHS OF DATA FILES. This submenu allows the user to tell FIRE SIMULATOR where to look for certain input files and where to store output files or search for those files for retrieval. Four files are covered as follows:

(i) FIRE FILES. These are files created either by the routines in MAKEFIRE or as an output of FIRE SIMULATOR. These files provide a rapid means of loading the data on the burning rates required by FIRE SIMULATOR and several of the FIREFORM routines.

(ii) INFILES. INFILES contain the input data describing the facilities for FIRE SIMULATOR. Once such a data file has been established, it can be recalled and reused or modified at the user's discretion.

(iii) FREEBURN DATA FILES. The FREEBURN routine in MAKEFIRE creates data files describing the arrangement of fuel packages used in that routine. Once such a data file is made, it can be recalled and reused or used as the basis for an adjusted FREEBURN input.

(iv) ASCII FORMAT FILE. The ASCII FORMAT FILE contains data output produced by FIRE SIMULATOR in columnar form ready for graphing routines. The ASCII FORMAT FILE can also save for later study items of data not shown in the printout of FIRE SIMULATOR. To select the data to be saved by the ASCII FORMAT FILE, go to the FIRE SIMULATOR main menu.

To change the path (i.e. the instructions to the computer identifying the disk drive and directory where the file resides or is to be stored) for any of these 
files, press the enter key while the highlight bar is on the item of interest. A description of the current path will appear in a box at the bottom of the page. To change the path, simply type in the new path. To exit this menu, move the cursor down to "done" and press the enter key. Users who may not be familiar with paths and directories as used by MSDOS should consult their MSDOS instruction manual.

\section{VIEW/EDIT SPECIAL PARAMETER FILES.}

The special parameter files are the PALLET FILE which controls the screen colors, the WARNING FLAGS FILE which controls the criteria for presenting warning flags on the screen and printout, and the CURRENT ASCII VARIABLE FILE which tells the ASCII FORMAT FILE which variables to track. To revise the path and/or name of any of these files, locate the highlight bar on the item of interest and press the enter key.

(i) PALLET FILE. The user will be given the option to modify the current PALLET FILE and/or select a different PALLET FILE from any previously assembled list and/or if the current pallet is changed, change the name of the pallet file. Screen prompts guide the user through this.

(ii) WARNING FLAGS FILE. This entry provides the user with the single option of selecting warning flags from any previously created WARNING FLAGS FILE. The initial default case instructs FPETOOL to show no warning flags. To create new warning flag files, use the main menu in FIRE SIMULATOR.

(iii) ASCII VARIABLES FILE. This entry works the same as the previous WARNING FLAG FILE. If additional ASCII VARIABLE FILES have been previously created, they can be called from this entry. The initial default file for the ASCII VARIABLE FILE instructs the ASCII FORMAT FILE to include time, smoke temperature, smoke level, and oxygen content in the smoke.

\section{h. Additional Guides for Individual Routines}

In FPETOOL, each of the routines has a menu requiring the entry of data or other information. An attempt has been made to provide guidance on the computer screen at the time the entry is required. This guidance generally occurs in $a$ box at the bottom of the screen. Of necessity, this results in relatively short messages. In some cases, where the information is obvious (e.g., ROOM CEILING HEIGHT (ft.)), no instructions are provided. The additional information provided in the following sections of the User Guide consists of further discussion on selected individual items. It is felt that such might be useful to some users.

\section{FIREFORM}

FIREFORM Menu. FIREFORM consists of seventeen different fire safety procedures. Each is a stand-alone procedure called from the main menu. While the menu does not provide extensive discussion of the individual procedures, 
the first computer screen presented when a FIREFORM procedure is called, discusses the purpose and capabilities of the procedure involved. Additional discussion of each prociedure follows:

a. ASETBX ROOM FIRE MODEL

(1) HEAT LOSS FRACTION. HEAT LOSS FRACTION is the estimated portion of total energy produced by the fire that is either lost (primarily by radiation) before the hot gases enter the upper layer of smoke plus that energy which after entering that hot layer is transferred out of it. Losses from the upper layer can be by radiation or by heat transferred to the ceiling or walls in contact with the hot gases. Since ASETBX assumes a closed room, no heat is lost by flow of hot gases out of the room. The higher the value of the heat loss fraction, the lesser the energy that stays in the fire gases. This affects both the amount of hot gas produced and the temperature of these gases. The impact on temperature is greater than the impact on quantity of smoke (or the resultant speed of descent of the gas layer). Cooper [1] provides some guidelines for selecting the value to be used. The range is normally between 0.6 (60\%) and about 0.95 (958). A value of 0.8 to 0.9 is generally recommended for those situations where the room height and width are of similar dimension. The value decreases as the width increases relative to the height and increases towards the maximum as the height increases relative to the width.

It is important that users recognize the impact of the selection made. For a heat loss fraction of 0.9 , ASETBX calculates the results on the basis of only $10 \%$ of the heat generated being available to increase the smoke temperatures. The value of 0.6 for this same factor causes ASETBX to calculate on the basis of $40 z$ of the heat generated remaining in the smoke. The difference between an entry of 0.9 and 0.6 is therefore four fold in terms of the heat content in the smoke layer.

If estimating the value of the heat loss fraction is unsatisfactory, the user should not use ASETBX. The program FIRE SIMULATOR in this package and other more sophisticated models that internally calculate the heat loss factor should be used instead.

(2) FIRE HEIGHT. The positioning of FIRE HEIGHT has a significant impact on the results. ASETBX assumes a point source plume with the source at the point defined as fire height. Changes in this height impact on the smoke temperatures by a factors slightly less then the square of the distance from the point of fire to the bottom of the smoke layer. The lesser the distance, the hotter the smoke entering into the smoke layer.

In setting this height, the user should, to the best of his ability, set the fire height at that point most closely approximating the bottom of the fire plume generated by the fire. As the message on the screen reads, this is roughly "THE LOWEST 
POINT WHERE BURNING WILL OCCUR AND FIRE CAN ENTRAIN AIR." For many items, this is the point of ignition. For others, where fire may extend down from the point of ignition, the user, depending on what stage of the fire is important to his analysis, may wish to pick a point different (presumably lower) than the point of ignition. In making such an appraisal, the user should consider that there must be an open space for air entry for the fire to entrain the air. Little or no air will be entrained on the side of a fire abutting a wall, the back of a chair, or other object obstructing the inflow of air.

b. ATRIUM SMOKE TEMPERATURE. In this procedure, the choice of CLEAR HEIGHT is made by the user. It is suggested the following be observed in making the choice.

(1) A means is established for maintaining the smoke level at the height used. The FIREFORM procedure PLUME FILLING RATE is one means of estimating the rate of smoke removal needed to accomplish this.

(2) CLEAR HEIGHT is no more than approximately twice the narrow dimension of the atrium involved. Above this level, the rising plume will meet the closest walls. This will restrict entrainment of cooling air. The result will be less heat loss and a higher than calculated temperature above the point of plume contact with the walis.

(3) CLEAR HEIGHT is sufficiently above the fire base so that cooling entrainment can occur. This routine calculates the approximate value and when a clear height is entered, indicates maximum fire size that should be considered. The value presented is that level of energy that, by the procedures in this routine, would produce an uppex level temperature of approximately $220^{\circ} \mathrm{F}\left(104^{\circ} \mathrm{C}\right)$.

c. BUOYANT GAS HEAD. The comments presented on the screen are felt sufficient for this procedure.

d. CEILING JET TEMPERATURE.

(1) THERE ARE NO NEARBY WALLS (first item in menu). This item is a toggle switch. There are three possible arrangements. The three options are:

\section{THERE ARE NO NEARBY WALLS \\ FUEL PACKAGE IS NEAR A WALL \\ FUEL PACKAGE IS IN A CORNER}

The menu moves from one item to another by pressing the ENTER key. When the desired message appears, move to the next entry by using the down arrow. A fuel package should be considered near the wall or in a corner only if it is close enough to that wall or corner to obstruct the entrainment of air on the side(s) of the fuel package 
facing the wall or corner. For furniture that is up against a wall, obstruction of entrainment air should be considered important only if the furniture is ignited in a position close enough to the wall to obstruct free entrainment of air into the fuel.

(2) DISTANCE FUEL TO CEILING. This distance should be set at that point most closely approximating the bottom of the fire plume generated by the fire. As the message on the screen reads, this is roughly "THE LOWEST POINT WHERE BURNING WILL OCCUR AND FIRE CAN ENTRAIN AIR." For many items, this is the point of ignition. For others, where fire may extend down from the point of ignition, the user, depending on what stage of the fire is important to his analysis, may pick a point different (presumably lower) than the point of ignition. In making such an appraisal, the user should consider that there must be an open space for air entry for the fire to entrain the air. Little or no air will be entrained on the side of a fire abutting a wall, the back of a chair that is burning on the face side, or where some other object obstructs the inflow of air.

e. CEILING PLUME TEMPERATURE. This procedure applies to points inside the plume. A point is considered inside the plume if the distance from the axis directly over the fire to the point of interest is less than $0.2 \mathrm{x}$ the height from the base of the fire to the elevation of that point.

(1) THERE ARE NO NEARBY WALLS (first item in menu). This item is a toggle switch. There are three possible arrangements. The three options are:

THERE ARE NO NEARBY WALLS

FUEL PACKAGE IS NEAR A WALL

FUEL PACKAGE IS IN A CORNER

The menu moves from one item to another by pressing the ENTER key. When the desired message appears, move to the next entry by using the down arrow. A fuel package should be considered near the wall or in a corner only if it is close enough to that wall or corner to obstruct the entrainment of air on the side(s) of the fuel package facing the wall or corner. For furniture that is up against a wall, obstruction of entrainment air should be considered important only if the furniture is ignited in a position close enough to the wall to obstruct free entrainment of air into the fuel.

f. EGRESS TIME. EGRESS TIME uses a slightly different menu than other routines in FIREFORM. To the left is a list of items. The cursor moves up and down the item values on the right. The first four items are default values included as approximations of the average for capable persons in well lit space in good condition. These are the essential constants used in the calculations. The user may change any he may wish. 
(1) FLOW RATE ON STAIRWAY (person/min./ft. of effective width). The default value 18.3 persons per minute per ft. of effective width has been derived from data developed from Pauls and presented in Appendix D of NFPA 101M [2]. Effective width is equal to the actual tread width less twelve inches. For wide stairs with intermediate rails, the space between each set of rails is considered as a separate path. The effective width of each portion is the width of that portion minus twelve inches.

(2) EVACUEES ARE ABLE. This item is a toggle switch. Press ENTER to change from "EVACUEES ARE ABLE" to "EVACUEES ARE DISABLED." If the entry is toggled to "EVACUEES ARE DISABLED," a new entry will occur on the following line of the menu reading "SPEED OF SLOWEST EVACUEE AS PERCENT OF THAT OF AN ABLE PERSON." The default value is 1008. The user may change this to any value larger than zero. The impact of changing this is to, internally in the calculations, reduce the travel speeds on both level and vertical routes proportionally to the evacuee speed entered. In essence, this assumes that the slowest person is both unassisted and at the most remote place in the evacuation route. If the situation is other than this, the user can account for it by using a speed factor that is proportionally adjusted for the distance that the disabled person will actually have to travel. EGRESS TIME will not work if a value of zero is entered. EGRESS TIME is not a rescue model. Such would be necessary if there were persons unable to move at all. If a value of zero is entered, a message to that effect will appear on the screen asking the user to enter a value greater than zero.

(3) EXIT DOOR LEAVES AVAILABLE TO EVACUEES. The number of exit doors leaves available is based on the minimum number that a stream of evacuees will encounter. For example, if a number of persons are leaving individual offices on several floors of a building to evacuate through a single stairwell, the number of leaves that is entered are those discharging from the stairwell at its base. Normally, this will be one unless there is a double set of doors at the base in which case it would be two. Similarly, if the population of a building were evacuating from a series of floors through two stairways, the number of leaves in the discharge from those stairways would be the number entered.

(4) PORTION OF TRAVEL OVER STAIRS (VERTICAL DISTANCE IN FT.). The entry made for this item is the vertical distance starting with the highest floor used by the evacuees to the level of discharge from the building. It is not a measurement of the actual distance traveled on the slope of the stairs. If a value is entered in this item, a series of additional entries will appear on the screen. Each of these are self explanatory but all need to be entered to successfully execute the program. 
g. FIRE/WIND/STACK FORCES ON A DOOR. This routine uses sub-menus that are accessed by using the left and right cursor arrow keys.

(1) PARAMETERS - The left hand sub-menu is titled "PARAMETERS." The items in this menu cover the dimensions of the door and the description of the surrounding smoke environment. This menu is also used to cause the calculations to begin. If the user does not wish to consider WIND or STACK EFFECTS, this is the only menu needed.

(2) WIND EFFECTS - To add WIND EFFECTS, use the cursor arrow key to move to the next sub-menu. Press the ENTER key if WIND EFFECTS are to be considered. Alternately press the ENTER key if previously considered WIND EFFECTS are not to be considered in the subsequent calculations.

(3) STACK EFFECTS - Use the cursor key once more to consider the impact of STACK EFFECTS. STACK EFFECTS are based on the height of the stack and the temperature difference between inside and outside the building. In this routine, the user is asked to ENTER the height of the building.

(a) BUILDING HEIGHT. In this calculation, a neutral plane is assumed to exist at $2 / 3$ the height of the building. The user may adjust for other situations by entering the value for height of the building that is $11 / 2$ times the distance between point of interest and the neutral plane of the building.

(b) LOWEST WINTER TEMPERATURE. The procedure is based on winter conditions. It assumes an internal building temperature of $70^{\circ} \mathrm{F}$ $\left(21^{\circ} \mathrm{C}\right)$. The winter temperature shown is the difference between that temperature, $70^{\circ} \mathrm{F}$, and the outside temperature.

NOTE: The impact of negative (hot summer) stack effect on the door can be approximated by entering a temperature that is as much colder than $70^{\circ} \mathrm{F}$ as the outside temperature is warmer. (For an inside temperature of $70^{\circ} \mathrm{F}$ in an outside temperature of $90^{\circ} \mathrm{F}$, enter a value of $70-20$ or $50^{\circ} \mathrm{F}$. The results in terms of impact forces on the door are the same. In the summer case, the flow would be in the opposite direction and the user should consider if it's additive or negative.)

h. MASS FLOW THROUGH A VENT. This routine is intended to describe the flow through an opening into a room which is already flashed over or otherwise is at a ventilation limiting condition. Normally, temperatures exceeding $500^{\circ} \mathrm{F}$ would be a minimum for use of this procedure.

(1) CONVERGENCE CRITERIA. MASS FLOW THROUGH A VENT uses an interim process to derive an approximate conclusion. CONVERGENCE CRITERIA sets the tolerance used to judge if the answer reached is in an acceptable range. The same value is also used internally in the process to determine the size of adjustment to be made in the 
equations being evaluated for each iteration. The larger the number, the faster and less accurate the calculation. The default value is 10\%. This can be adjusted by the user. For those with faster computers, a simple adjustment to the convergence desired will quickly produce the desired results. For those with slower computers, it is advisable to initially run the procedure at the $10 \%$ convergence value and then repeat the calculations at $1 \%$ continuing this step procedure until the convergence value desired is reached. This will normally reduce the number of iterations by about a factor of 10 .

(2) UPPER LAYER TEMPERATURE. This procedure is designed for fully involved rooms with high temperatures. It is inappropriate for lower temperatures. Most of the data developed was derived in post-flashover conditions with temperatures in excess of $1000^{\circ} \mathrm{F}$. As the temperature gets less, the likelihood that the answer is valid becomes less.

(3) BURNING RATE. This is the burning rate in grams per second. Depending upon the heat of combustion and the material burned, each gram per second represents between about 15 and 35 kilowatts. The value entered should be approximately the burning rate of the material involved. If the user believes that there is more material bejng pyrolyzed than there is air available to burn that material, he should add that additional mass to the burning rate calculations. In most instances, however, the mass involved in the burning of the material is a relatively minor part of the total mass movement and erroxs in this area are usually of limited significance.

i. LATERAL FLAME SPREAD. This procedure estimates the speed of flame travel over an unburned combustible surface in a direction away from the flame. It is not appropriate for flame spread along that portion of the material covered by the flame or the flow of hot gases in front of that flame. The execution of this formula requires specific variables. The procedure was developed specifically by test procedures for the LIFT apparatus [3]. For best results the variables used should also be derived from that test. In any case, the variables used for $\mathrm{PHI} / \mathrm{k} \rho \mathrm{c}$ should be derived from a single test. The user should understand the value of $k \rho c$ used in this procedure is an effective thermal inertia at the burning temperatures involved and is not the same as that derived by multiplying the individual values of the thermal physical properties at room temperature normally found in standard reference texts.

(1) LIST VALUES FOR THESE VARIABLES. This is a toggle key. Pressing the ENTER key when this item is highlighted brings up a table of values that have been derived from the LIFT apparatus. At the bottom of the screen is a prompt reading, "DO YOU WANT TO ENTER $\mathrm{PHI} / \mathrm{K} \rho \mathrm{C}$ NOW? $(\mathrm{Y} / \mathrm{N})$." Entering a yes answer brings up the prompt, "ENTER VALUE FOR PHI/K $\rho \mathrm{C}$," the user may then refer to the data on the table entering a value for $\mathrm{PHI} / \mathrm{K} \rho \mathrm{C}$ from the table, from another reference source, or as an estimate based on comparison to other 
materials in the table. When he makes that entry and presses the ENTER key, a second prompt appears worded "DO YOU WANT TO ENTER IGNITION TEMPERATURE NOW? (Y/N)." A yes answer will follow the same procedure for ignition temperature as previously done for $\mathrm{PHI} / \mathrm{K} \rho \mathrm{C}$. When this is completed, the program returns to the main menu. Alternatively, the values can be entered directly without going through the list of variables.

SURFACE TEMPERATURE. Flame spread is based on the difference between the surface temperature of a material and it's ignition temperature. SURFACE TEMPERATURE is frequently a difficult value to obtain. A first order estimate can be made by using the gas temperature of the smoke next to the surface. This is a conservative estimate and if the temperature is rising rapidly, the actual surface may be considerably cooler than the smoke or hot gases adjacent to it. In such a case it should be expected that flame spread will be slower than the calculated speed.

In any case where the surface temperature is entered at a value equal or higher than the ignition temperature, immediate ignition of the surface is assumed.

j. LAW'S SEVERITY CORRELATION. Following menu items that input the dimensions of the space in the opening is an item titled, "FIRE LOAD AS TOTAL POUNDS IN SPACE." This is a toggle switch. Pressing the ENTER key when this item is highlighted will change it to "FIRE LOAD AS LBS/SQ. FT." This provides the user with the option of entering Fire Load as either the total fuel in the space or the density in $1 \mathrm{bs} / \mathrm{sq}$.ft. of fuel in the space. The program will not accept a fire load entry until length, width, and height of space have been entered.

k. PLUME FILLING RATE. The volume flow in a smoke plume consists primarily of the air entrained by the rising buoyant hot gases. While the amount of air entrained is dominated by the entrainment height, it is also a function of the amount of energy released by the fire and retained in the rising gases. This routine accounts for that fraction by tallying the portion of energy that leaves the plume. Two entries accomplish this:

(1) RADIANT FRACTION. RADIANT FRACTION accounts for the energy lost by radiation. This is directly related to the sootiness of the flame.

(2) OTHER LOSS FRACTION. OTHER LOSS FRACTION is provided to account for other losses that may occur due to conduction or convection of energy out of the plume. This is normally a lesser amount than the radiant fraction.

1. RADIANT IGNITION OF A NEAR FUEL. This procedure presumes an exposure fire which is gruwing and which will produce energy rates beyond that indicated as that expected to cause ignition by this procedure. It is not appropriate for a long duration steady state exposure. The second entry in this procedure is a toggle switch. Initially, it states "FUEL IS NORMALLY RESISTANT TO IGNITION." Pressing the ENTER key changes the 
statement to "FUEL IS DIFFICULT TO IGNITE." Pressing the ENTER key again changes the statement to "FUEL IS EASILY IGNITED." Continued pressing of the ENTER key cycles through these same three options. The message at the bottom of the screen explains each of the options. Pressing the down arrow on the cursor pad to moves the highlight bar to the next entry.

m. SMOKE FLOW THROUGH OPENING. This procedure presumes an opening where the cross sectional area is reasonably large relative to the length of the opening. For most openings down to about the size of an average door gap this is approximately correct. Tight fitting doors such as those designed to stop smoke or cracks in walls or other situations where the opening has a relatively long length of path as compared to its cross section opening should not be appraised with this routine. Comments on individual entries follow:

(1) SMOKE FLOW AREA. If the opening is rectangular, circular or another single shape, the entry is the actual area of the opening. If an attempt is being made to measure smoke flow through an irregular opening (such as the crack around a door), the opening should be divided into segments of regular shapes and each one calculated separately. Where the opening is vertical and the smoke layer covers only part of the opening, the smoke flow area is that area of the opening above the smoke layer.

(2) SMOKE TEMPERATURE. This routine presumes that there is a single temperature of the smoke from the top of the opening to the base of the smoke level. It cannot handle a situation where the temperature of the smoke varies.

(3) DEPTH OF SMOKE. DEPTH OF SMOKE is measured from the bottom of the smoke layer to the hydrostatic center of the opening. Where the opening is horizontal (as in a ceiling) this measurement is from the bottom of the smoke layer to the plane of the opening. Where the opening is vertical and the smoke layer covers only part of the opening. This measurement is from the bottom of the smoke layer to a position approximately $4 / 9$ of the distance from the bottom of the smoke layer to the top of the opening. Where the smoke is below the bottom (sill) of the opening, the depth of smoke is the distance from the bottom of the smoke layer to a point approximately $4 / 9$ the distance of the sill of the opening to the top of the opening.

n. SPRINKLER/DETECTOR RESPONSE. This routine is designed for unconfined ceilings. That is locations where there is no significant buildup of hot gas below the ceiling. Where such a heat buildup is expected, the device may respond faster than indicated by this routine. The routines in FIRE SIMULATOR are better suited for such situations. The routine also does not consider any conductive losses such as can occur between a sprinkler head and the water pipes supporting it in the case of a slow developing fire. Where such occurs response to the device may be slower than that indicated by these calculations. Discussion of individual entries follows : 
(1) HEIGHT OF CEILING ABOVE FIRE. As indicated in the help note, this is the distance from the lowest point where burning is expected and the fire can freely entrain air to the ceiling. In estimating this distance, it is suggested that the point of ignition be used unless it is expected that there will be a long delay from the moment of ignition to activation of the detection element. In such case, the user should adjust this to the point he believes that the distance from the base of the fire to the ceiling will be at the time of activation of the detection element.

(2) DETECTOR RESPONSE TIME INDEX (RTI). The response time index is a measurement of the delay of the device in responding to a flow of hot gas due to its mass, material, and configuration. The help message shows typical rti values (in english dimensions) for common classes of sprinkler heads. It is also possible to make a first order approximation of the response of a smoke detector by assuming that a temperature rise of about $18-23^{\circ} \mathrm{F}\left(10-13^{\circ} \mathrm{C}\right)$ for a response device with a response time index of 0 approximates a condition at which a smoke detector would respond. The user should be cautioned however that this program does not account for the travel time from the generation of the smoke at the point of combustion to the detector. Where devices are relatively close to the fire source this is a negligible factor. Sometimes, however, smoke detectors are located a considerable distance from the source of ignition. In such cases, the error caused by this limitation can be significant. The user can use FIRE SIMULATOR to exercise the same problem in which case FIRE SIMULATOR reports the velocity of the jet at the point of the detection device. This can be helpful in making first order estimates of the transit time not accounted for in this calculation.

o. THOMAS' FLASHOVER CORRELATION. To operate THOMAS' FLASHOVER CORRELATION, the user simply enters the dimensions of the room and of a single opening.

p. UPPER LAYER TEMPERATURE.

(1) ROOM LINING MATERIALS. The UPPER LAYER TEMPERATURE calculation includes determination of heat losses to the walls based on the area, the specific properties of the material involved, and the thickness of that material. Pressing the ENTER key when this item is highlighted will bring up a prompt reading "NUMBER OF LINING MATERIALS OR THICKNESSES (UP TO 5) $="$. UPPER LAYER TEMPERATURE calculation makes an estimate of the loss of energy to the room lining based on the surface area of that lining and the thermal physical properties and thickness of the material involved. UPPER LAYER TEMPERATURE formula can consider up to five different surfaces. It does not have the ability to consider the thermal characteristics of surfaces that are built up of successive layers of different materials. In such case, the user must either make an approximation or elect to use the principal constituent of exposed surface (for materials like plaster or gypsum board covered with paint or wallpaper, you would normally use the plaster or gypsum board properties). It is suggested that the surface area entered cover all of 
the surfaces (walls, ceiling, and floor) of the space except those surfaces that are expected to be either on fire or covered by a burning item.

When a value is entered for the number of surfaces (any number from one to five), a material catalog will appear on the screen. The catalog lists twenty different typical wall lining materials. It also includes an entry titled, "OTHER MATERIALS NOT LISTED." This same catalog is used in FIRE SIMULATOR. A catalog adjustment program is available. It is called from the main menu for FIRE SIMULATOR. In that menu there is an item entitled, "LINING MATERIALS." The program called up by that item can be used to revise this catalog. A material is selected from the catalog by moving the highlight bar to that material and pressing the ENTER key. The screen will then display a list of the thermophysical properties contained in the catalog for that material. At the bottom of the screen is a question, "IS THIS THE MATERIAL YOU WANT $(\mathrm{Y} / \mathrm{N})$." If it is, enter $Y$, if not, $N$.

If the material is chosen, the next screen asks first for the thickness of the material in inches. When that value is entered, a second message appears asking for the area of that material in square feet.

If none of the materials in the catalog are appropriate, the user moves the highlight bar to the item entitled, "OTHER MATERIALS NOT LISTED" and presses the ENTER key. This brings up a screen that asks first for a name, then the thermal conductance of the material, the thermal inertia of the material $(k \rho C)$, the thickness of the material in inches, and the area in square feet. When these have been completed, the program returns to the data entry menu for upper level temperature.

(2) VENTS. UPPER LAYER TEMPERATURE calculation must have an entry for vents to run. When the highlight bar is placed on the line entitled VENTS and the ENTER key is pressed, a sub-menu appears entitled VENTS. The menu calls for the user to enter the dimensions of two vents. The vents are arbitrarily entitled DOOR and WINDOW. In actual fact, they can be any openings and are treated by the program as simply two vents.

(a) HEIGHT. HEIGHT, in each case, is from the bottom or sill of the opening to the top of that opening. HEIGHT is not measured from the floor unless the bottom of the opening is at the floor. If the user enters data for only one opening, the program will proceed on the basis of a single opening. If the enters data for two openings, it will calculate both openings. It makes no difference which of the two opening entries are chosen.

(3) FIRE FILE. This prompt calls up instructions that allow the user to specify the rate of heat release from the exposing fire. The entry may be from a previously created fire data file or may be entered by the user as a series of individually entered fire data points. The screen instructions are felt to be a sufficient guide.

(4) Flashover Prediction. If the computations in the program predict that the temperature in the upper level gas reaches $1112^{\circ} \mathrm{F}\left(600^{\circ} \mathrm{C}\right)$, the 
program will stop and assume that flashover has occurred. The user is given the option of stopping the program or continuing. If the program continues, it will no longer calculate rate of heat release based on the entry made by the user but assume that many items have ignited in the space and that there is more than enough fuel to consume all of the oxygen available through the openings. The user is given an opportunity to revise both the openings and the lining material composition. This is to give the user an opportunity to make adjustments that he believes may have occurred as a result of the transition into the flashed over stage.

q. VENTILATION LIMIT. No help messages are necessary for this routine.

\section{MAKEFIRE}

All of the routines in MAKEFIRE are designed to develop fire data files to be used by other routines. Within FPETOOL, the fire data files developed can be used by ASETBX, SPRINKLER/DETECTOR RESPONSE, UPPER LAYER TEMPERATURE, and FIRE SIMULATOR. Users may also find MAKEFIRE useful in developing input data files required by other computational procedures such as HAZARD I.

a. FORMULA. Computer screen messages within this program provide detailed instructions for its use and additional user guides are not considered necessary.

b. FREEBURN. FREEBURN is a method to allow the user to combine up to five fire data files representing individual fuels into a single file representing their cumulative effect. The fire data file produced is the sum of the individual burning rates with the burning rate of each additional item starting at a calculated point of ignition. As shown on the first screen, FREEBURN does not include any mechanism for considering any enhancement of burning that can occur due to the energy imposed on one burning fuel from another or on the entire collection from an external source such as the hot ceiling layer. If the user wishes to consider such, based on judgment or other data the user must create a fire data file (the program MYFIRE can be used for this purpose) describing the enhanced burning rate to be considered by FREEBURN.

FREEBURN requires the user to provide a considerable amount of data regarding the individual fuel packages to be considered, individual dimension information on the packages, their separation, and data regarding the expected radiation from their flames and the ignition factors. To allow the user to visualize this in the single screen, FREEBURN calls for the user to input most of the required data in a single matrix screen. Each of the items in that screen has a help message that describes the requirements. Most of these help messages are self explanatory. The help messages are called up by pressing function key Fl. The user moves around the items on the screen using the cursor arrow keys. 
c. MYFIRE. MYFIRE allows the user to create a sequential fire data file that describes the free burn course of a fuel package. Extensive instructions are given on the computer screen with this program and no additional user's information is provided.

d. LOOK-EDIT. LOOK-EDIT allows the user to review and if desired change any fire data file stored on any disk in the computer being used. The specific instructions appear on the screen. A special help feature is included in LOOK-EDIT. If the user wants to review the edit commands, pressing function key $F 1$ when the file listing is on the screen will call up a window showing the commands that must be used.

4. FIRE SIMULATOR.

FIRE SIMULATOR is accessed through the Main menu. Placing the selection bar over the title FIRE SIMULATOR will show the menu of options. As the user moves the highlight bar from item to item on the menu, a message appears below the menu giving a brief description of the item highlighted.

\section{a. FIRE SIMULATOR.}

FIRE SIMULATOR is the single largest element of FPETOOL. FIRE SIMULATOR is a simple fire condition estimating model designed to estimate the temperature and volume of the smoke layer produced by a fire, the venting of hot gas and combustion products from openings in that room, the response of heat actuated devices, sprinklers or heat detectors, and smoke detectors inside an environment, the oxygen, carbon monoxide, and carbon dioxide concentrations in the smoke, and the effects of available oxygen on the combustion process.

FIRE SIMULATOR is designed to estimate conditions in fires in both the pre- and post-flashover realms of burning. The user is required to describe the geometry and materials of the space involved, provide key parameters for any sprinklers or detectors he wishes to track, and provide a description of the initiating fire. Once a description (case) has been described, it is saved in a file that can be called up for reuse or as a basis for adjusting to create a new case.

FIRE SIMULATOR is called by moving the highlight bar to "FIRE SIMULATOR" and pressing the ENTER key. This brings up the FIRE SIMULATOR operating menu. This menu has five items on it.

(1) CREATE/REVISE CASE - Press ENTER when the highlight bar is on this item to create a new case or to revise a previously existing case.

(2) RUN EXISTING CASE - Move the highlight bar to this menu item and press ENTER to bypass the input sections brought up by the previous item on the menu and run a previously described case. Under this option, the user cannot make any changes to that case file. He 
can, however, make certain changes that are called for at the time of running such as turning the printer off or on, calling for an ASCII file to be made or responding differently than prior runs to "halt" commands or post-flashover descriptions.

NOTE: The next three menu items ("ASCII FILE," "LINING MATERIALS," and "HAZARD WARNINGS") control settings within FIRE SIMULATOR. It is expected the user will address these three files the first time he operates FIRE SIMULATOR but return to them only on occasions where he is interested in adjusting the special values generated by them.

(3) ASCII FILE. FIRE SIMULATOR will (at the discretion of the user) produce a file of variables saved in an ASCII format suitable for use on spread sheets and graphing programs. As presently programmed, FIRE SIMULATOR can save twelve variables on any run. Four of these (time, smoke temperature, smoke level, and oxygen concentration in smoke) are fixed. The user is given the option of choosing the other eight from a selection of twenty-eight items generated by the program. Highlighting the entry ASCII FILE and pressing ENTER brings up an instruction screen. Striking ENTER again brings up the selection menu. As the cursor moves the highlight bar across the selection menu, a brief help message appears below the menu for each item. Most are self explanatory. The following additional explanations for some of the items may be useful.

(a) L.FRAC. (Heat fraction use). FIRE SIMULATOR calculates the heat loss within the room for each iteration of calculations (normally one second). This is divided by the heat release rate to determine the loss fraction. FIRE SIMULATOR places limits on the maximum heat loss fraction. The value reported is that actually used by FIRE SIMULATOR considering both the calculation and the limits.

(b) L.FRAC.CAL. (Heat loss fraction calculated). This variable reports what the heat loss fraction would have been had it been based solely on calculations within FIRE SIMULATOR without considering the prescribed limits. Comparing this to the preceding parameter allows the user to review where and to what extent the imposed limits played a part in the calculation.

(c) RHR. (Heat release rate in room in $\mathrm{kW}$ ). This variable reports the rate of heat release FIRE SIMULATOR determines to have occurred within the room of origin. This is not necessarily the same as the rate of heat release entered as an input by the user. It may be adjusted if ventilation limiting conditions occur.

(d) MASS LOSS (Mass loss rate in $\mathrm{kg} / \mathrm{s}$ ). This variable reports the actual rate of mass loss of combustible material used by 
FIRE SIMULATOR. In the pre-flashover portion of the fire, this is calculated by dividing the rate of heat release entered by the user by the heat of combustion. In the postflashover portion, this is calculated by using heat of gasification and incident energy to determine the rate of mass loss for unit area of exposed combustible surface and multiplying this by the combustible surface prescribed by the user.

(e) ENTRAIN (Entrainment limit in $\mathrm{kW}$ ). This variable tracks the amount of combustion that can be supported by the air entrained in the portion of the plume below the smoke layer. This assumes 218 oxygen in that air. This factor has no effect on the calculations unless the prescribed rate of heat release (as entered by the user) is greater than can be supported by the entrained air and the level of oxygen in the smoke layer is below the minimum required for combustion in the smoke layer and as calculated by FIRE SIMULATOR based on the limits entered by the user.

(f) ENTMASS (Entrained mass in $\mathrm{kg}$ ). This variable plots the mass of air entrained in that portion of the fire plume below the smoke level.

(g) 02 REQ (Oxygen required in vol\%). This variable plots the minimum level of oxygen required for combustion in the smoke layer as calculated by FIRE SIMULATOR based on the limits specified by the user.

(h) VENTED KW (Total vented energy in $\mathrm{kW}$ ). This variable plots the enthalpy (residual energy due to the elevated temperature) in the smoke vented from the room. This value is the total of all such energy that may be vented through either of the openings that the user is allowed to prescribe or through any prescribed HVAC system.

(i) VENTl $\mathrm{KW}$ (Energy vented to the inside in $\mathrm{kW}$ ). This variable plots that portion of the vented enthalpy exiting through the opening described by FIRE SIMULATOR as inside opening. This is the same value that is reported as enthalpy in the printout of FIRE SIMULATOR.

(j) VENT2 KW (Energy vented to the outside in $\mathrm{kW}$ ). This variable plots any energy that is vented from a second opening. FIRE SIMULATOR assumes that such an opening is to the building exterior and does not report it in the screen or hard copy printout.

(k) HVACVENT KW (Energy vented through the HVAC system in $k w$ ). This variable plots that enthalpy that is removed by any prescribed HVAC system. 
(1) VISION (Vision distance in $\mathrm{ft}$ ). This is approximate vision distance at which the smoke would have an optical density of about 1.5 ( $97 \%$ obscuration). It is probable that this point is the maximum distance at which a well lit exit sign or daylight could be discerned.

(m) SMKFLOW1 (Smoke flow inside in $\mathrm{cfm}$ ). This variable plots the rate of flow from the burning room through the opening designated as inside opening by the user.

(n) SMKFLOW2 (Smoke flow outside in $\mathrm{cfm}$ ). This variable plots the volume flow of smoke through the outside opening if the user has designated such an opening.

(o) RM. LIN. F (Temperature of room lining in ${ }^{\circ} \mathrm{F}$ ). This variable plots the temperature of that portion of the room lining in contact with the smoke layer as estimated by FIRE SIMULATOR. The calculation is an average temperature. If several materials are involved, the reported temperature is a weighted average based on the relative amount of each material. Where multiple materials are involved, it is likely that the temperature reported is not the actual temperature of any single material.

(p) VENT. LIMIT (Ventilation limit in $\mathrm{kW}$ ). This variable plots the ventilation limit. The ventilation being the maximum amount of combustion that can be supported by the air brought into the room by the room openings or by the HVAC system. This value is a limit state. FIRE SIMULATOR will not allow the maximum rate of heat release to exceed that determined by this value. The value will change any time the user causes doors to be opened or closed or the HVAC system to be turned on or off.

(q) SMK. RAD. (Radiation from Smoke in $\mathrm{kW}$ ). This variable calculates the total amount of energy lost by radiation from the smoke layer. The radiation is lost to that portion of the room in contact with the smoke layer and from the bottom of the smoke layer to the other portions of the room or out any openings.

(r) CONV.LIN. (Convected energy from smoke in $\mathrm{kW}$ ). This variable actually includes both the convected and conducted transfer of heat from the smoke body to that portion of the room lining in contact with it.

(s) VENT FLOW (Total vent flow in $\mathrm{kg} / \mathrm{s}$ ). This variable plots the total of all mass vented through openings or the HVAC system. It includes both the mass of the hot gas plus any mass of unburned fuel. 
(4) LINING MATERIALS. Placing the highlight bar over the menu item LINING MATERIALS and pressing the ENTER key calls up the material catalog. This catalog lists all of the lining materials currently in the memory of FIRE SIMULATOR. With this editor, the user can review the values currently in the memory for thermal conductivity, density, specific heat, and emissivity for the materials listed. With the editor, he can change any of the values, add or delete a material, or print out a listing of these values for all of the materials in the catalog.

(5) HAZARD WARNINGS. Locating the highlight bar on the FIRE SIMULATOR menu over HAZARD WARNINGS and pressing the ENTER key will bring up the catalog of warning flags. As delivered, all the warning flags are turned off. The user may set any critical value desired for the warning flags. Once a value has been set, FIRE SIMULATOR will present on the screen and in any hard copy printout a warning message the first time that the prescribed hazardous condition occurs. It will also print out the details of the environmental conditions at that moment whether or not that matches the user prescribed interval for screen displays and hard copy printout. All of the conditions tracked are conditions that occur in the smoke layer.

(a) The user is given two options for temperature.

The first, labeled "TEMPERATURE (above $5 \mathrm{ft}$ )" is provided so the user can set a temperature level at which it is believed that radiation from the hot gas will be the criteria for danger. Normally, this is a higher temperature than that which would be critical for body contact or inhalation of the hot gas.

The second, labeled "TEMPERATURE (below $5 \mathrm{ft}$ )" is provided for the user to input temperatures felt to be dangerous involved in body contact or inhalation. This is normally a lesser temperature.

(b) There are also two separate inputs labeled "VISION DISTANCE 1" and "VISION DISTANCE 2." FIRE SIMULATOR will bring up a warning whenever the calculated vision distance through the smoke drops to a level where 95 to $97 \%$ light obscuration occurs through the smoke at the distance entered. Two levels are provided so that the user may have a shorter and longer distance. Such might be of interest to compare the time when vision would be difficult down the length of a corridor versus that from the door into a small office.

b. Creating a new FIRE SIMULATOR case.

To create a new program, call up the item labeled CREATE/REVISE CASE. A screen will appear listing any previously developed case files. In FIRE SIMULATOR, case files are all identified with a file name having the extension ".in". 
The highlight bar will be in the upper left hand corner of the listing on an entry entitled CREATE NEW. To create a new file, press ENTER at this time.

A series of input screens will appear. For the most part, these screens are self explanatory or contain necessary guidance in help messages occurring on the screen. The following comments, however, provide additional information for selected items where that expanded comments may be helpful to the user. Where the screen presented data is believed to be complete no additional discussion is provided.

(1) DEFAULT VALUE - HEAT OF COMBUSTION. In general FIRE SIMULATOR uses the rate of heat release as provided by the user or revised by FIRE SIMULATOR in recognition of oxygen limitations in its calculations. Heat of combustion is used in those instances where it is necessary to know the mass burning rate (such as the estimation of vision distance) and in the post flashover calculation of rate of heat release. FIRE SIMULATOR is not capable of calculating heat of combustion from entered fire data files. FIRE SIMULATOR operates on the assumption of a constant heat of combustion in both the preflashover and post flashover phases. An opportunity is provided for the user to change the constant at the time of flashover. This is done in recognition of the frequent change in the materials actually burning between the two phases.

(2) DEFAULT VALUE - CRITERIA FOR ASSUMING FLASHOVER. FIRE SIMULATOR uses the upper layer (smoke) temperature to determine that flashover has occurred. The default value used is $1112^{\circ} \mathrm{F}\left(600^{\circ}\right.$ C). This is felt to represent a condition where the full involvement driven by flashover has been established and it is expected that most exposed combustible surfaces in the room have become ignited. Those seeking an indicator of the onset of flashover may choose a lower temperature (say $900^{\circ} \mathrm{F}$ or $500^{\circ} \mathrm{C}$ ) as the indicator. The actual calculation procedures in FIRE SIMULATOR are the same for both the pre- and post flashover phases. The reason for highlighting the event is to allow the user to revise the description of both the burning condition and the room openings to recognize changes in both of these factors that often accompany flashover.

After FIRE SIMULATOR detects flashover, the user provides data on the available burning surfaces. This data is used to establish new rate of heat release information. Also after flashover FIRE SIMULATOR assumes that there is no heat losses from the smoke layer to any burning surfaces. (In the pre-flashover phase FIRE SIMULATOR assumes that the surface area of the burning material as compared to the total surface area of the room is small and neglects this factor.) FIRE SIMULATOR can be set to continue to use the initially specified fire past the development of flashover condition by setting the flashover temperature at a very high value (say $5000^{\circ}$ ). In such case, the breaking of a window or other 
change in the room vents (openings) can be simulated by calling for a "Halt" at the time the user wishes to assume such an occurrence. This approach should be used only where the room linings (walls and ceiling) are essentially noncombustible as FIRE SIMULATOR will assume heat loss to all of the room surfaces. When this approach is used FIRE SIMULATOR assumes that the fire source is a simple point source plume and will continue to limit combustion if it calculates an oxygen starvation condition in the smoke layer.

(3) DEFAULT VALUE - OXYGEN STARVATION CRITERIA. In the pre-flashover phase FIRE SIMULATOR upon development of oxygen starvation conditions in the smoke layer will limit combustion to that supportable by air entrained into the portion of the plume below the smoke layer. The ability of fuel and oxygen to combine and burn in an oxygen deficient atmosphere is known to be a function of the temperature of that atmosphere. At higher temperatures the minimum oxygen requirement is less. In some high temperature cases the fire is able to consume $100 \%$ of the oxygen. FIRE SIMULATOR assumes post flashover conditions as such. In the pre-flashover phase FIRE SIMULATOR assumes that the ability of the oxygen in the smoke layer to support combustion ceases if the oxygen drops below the calculated level. The level calculated is based on the values set for OXYGEN STARVATION CRITERIA. FIRE SIMULATOR calculates the critical value at each predicted smoke temperature as a linear interpolation between the two entries (room temperature and flashover temperature.) It is not known if the actual relationship is linear but no other approach is yet established. The presentation on the screen is given in terms of temperature. The first (room temperature) is fixed at $70^{\circ} \mathrm{F}\left(21^{\circ} \mathrm{C}\right)$ by FIRE SIMULATOR. The second (flashover temperature) shows the temperature set as the flashover criteria and will vary if the user varies the flashover temperature criterion. This relationship seldom comes into play until the fire is well developed and smoke temperatures are around $500^{\circ} \mathrm{F}\left(260^{\circ} \mathrm{C}\right)$. And then only if both smoke level and oxygen concentration conditions indicate an oxygen starved condition.

Also if the smoke layer descends below the level of the fuel, FIRE SIMULATOR will cease calculating and stop the program if the condition lasts longer than 5 seconds and the oxygen level in the smoke is less than that specified for minimum oxygen at $70^{\circ} \mathrm{F}$. The 5 second delay has been included because FIRE SIMULATOR will occasionally undergo a brief period of unstable cycling at the time of a sudden change in conditions (such as flashover or opening of doors or windows in a well developed fire situation.) These cycles are due to the solution numerics used and not a reflection of fire phenomena. The provision of a 5 second delay in recognizing the smothering condition is to avoid inappropriate shut down of the run.

(4) DEFAULT VALUES - CARBON MONOXIDE/CARBON DIOXIDE RATIO. The default values presented are near the upper limit of the $\mathrm{CO} / \mathrm{CO}_{2}$ ratio 
detected in test fires. FIRE SIMULATOR assumes that the shift from the lower to higher ratio occurs instantly any time the air supply is insufficient for free burning combustion. While the change is known to move rapidly toward the upper limit as the air supply available to the air supply required ratio decreases, it is not instantaneous, as calculated by FIRE SIMULATOR. If the user believes that the air suppiy is only sightly deficient, he may want to use a lower $\mathrm{CO} / \mathrm{CO}_{2}$ ratio for vitiated burning. A first order estimate of the relationship of air supplied to that needed can be obtained by comparing the rate of heat release reported by FIRE SIMULATOR to the rate of production reported for unburned fuel. The rate of heat release divided by the sum of the rate of heat release and the rate of production of unburned fuel approximates ratio of the air supply available to the air supply required.

(5) DEFAULT VALUES - HEAT TRANSFER FACTORS. The maximum heat transfer factor has a default value of 0.95 . The user should understand:

i. FIRE SIMULATOR calculates heat loss transfer each second. The maximum value is, therefore, not necessarily the actual value used. The ASCII file can be used to track both heat loss transfer calculated and heat loss transfer used.

ii. If the smoke temperature is greater than $572^{\circ} \mathrm{F}\left(300^{\circ} \mathrm{C}\right)$ and the fire is either growing or at a steady state the maximum heat loss factor is 0.8 .

iii. If the fire is decaying (the rate of heat loss is dropping) the heat loss factor is not limited and may readily exceed 1.0 .

iv. As the dimensions of the ceiling compared to the distance from the fire to the ceiling increase the heat transfer assumptions in FIRE SIMULATOR become less accurate. A message to the user will appear warning the user of this if the square root of the ceiling area exceeds 4 times the distance from the fire to the ceiling. A lower maximum heat loss factor is appropriate in such case. No absolute rule is available, however, it is suggested that the value should be lowered to not less than 0.6 in cases where the above ratio exceeds about 10 .

(6) OPEN DOOR, WINDOW, OR OTHER OPENING. FIRE SIMULATOR will operate with or without a prescribed opening. If no opening is prescribed FIRE SIMULATOR assumes that there is a floor level leak sufficient to avoid pressure buildup due to expanding hot gases.

FIRE SIMULATOR will accommodate two openings, one called inside and the other referred to as outside. The only difference is that FIRE SIMULATOR tracks the flow of hot gases and unburned fuel emitting from the inside opening but not from the outside opening. The input at this stage covers only the inside opening. If the user 
wants to specify an outside opening prior to flashover a time based halt should be specified. If the outside opening is to be open from the start of the fire specify a time based halt at say 20 seconds. The outside opening can then be specified when the case is run.

(7) SPACE DIMENSIONS. The data entries under this heading describe the room dimensions and the elevation of the fire in the room.

i. FIRE HEIGHT (ft.) The positioning of FIRE HEIGHT has a significant impact on the results. FIRE SIMULATOR assumes a point source plume with the source at the point defined as fire height. Changes in this height impact on the smoke temperatures by a factor slightly less then the square of the distance from the point of fire to the bottom of the smoke layer. The lesser the distance, the hotter the smoke entering into the smoke layer.

In setting this height, the user should, to the best of his ability, set the fire height at that point most closely approximating the bottom of the fire plume generated by the fire. This is roughly the lowest point where burning will occur and fire can entrain air. For many items, this is the point of ignition. For others, where fire may extend down from the point of ignition, the user, depending on what stage of the fire is important to his analysis, may wish to pick a point different (pxesumably lower) than the point of ignition. In making such an appraisal, the user should considex that there must be an open space for air entry for the fire to entrain the air. Little or no air will be entrained on the side of a fire abutting a wall, the back of a chair, or other object obstructing the inflow of air.

ii. IS ROOM RECTANGULAR? ( $\mathrm{Y} / \mathrm{N}$ ). FIRE SIMULATOR allows the user to enter the description of the room shape either in terms of length and width (if the room is rectangular) or in terms of floor area and wall perimeter if the room can not be described as a single rectangle. This non rectangular option is useful for $L$ shaped rooms or spaces with foyers or alcoves.

(8) HEAT RELEASE DATA. FIRE SIMULATOR allows the user to either call up a previously developed fire data file or to enter the input fire as a series of times and corresponding heat release rates. Fire data files are those previously created by MAKEFIRE or as an output of FIRE SIMULATOR. Once a fire has been entered, the data points are incorporated into the case file. Where they are individually entered by the user, the data points will be presented on any printout used but are not shown on the recapitulation screen. Where the data is acquired from a fire data file, only the name of 
that fire data file appears on either the printout or the recapitulation.

(9) HALTING THE PROGRAM. FIRE SIMULATOR provides the opportunity of causing the program to halt to allow the user to change the configuration of openings. There is a built in halt at the moment of flashover. This will occur whether or not the user makes any entry. In addition, the following three halts can be called:

i. HALT AT A SPECIFIED NUMBER OF SECONDS (SIMULATED TIME) INTO THE RUN. The user can specify this to simulate an action of an occupant or other action causing the opening or closing of a door or window independent of flashover at the any activation of a sprinkler or detector.

ii. HALT AT SMOKE DETECTOR ACTIVATION or AT A SPECIFIED NUMBER OF SECONDS AFTER SMOKE DETECTION ACTIVATION. Such might be used to simulate the sounding of the smoke detector alarm and automatic closing of a door or conversely the sounding of the smoke detector alarm with a time lapse to simulate the response of a person to open or close a door or window.

iii. HALT AT SPRINKLER/DETECTOR ACTIVATION or AT A SPECIFIED NUMBER OF SECONDS AFTER SPRINKLER/DETECTION ACTIVATION.

(10) DATA FILE NAME - FIRE SIMULATOR will save the information entered to create a case file in a data file having the extension ".IN" TOOL-IN.IN is the default name for that file. If there is a desire to save the file for future use, this name should be changed. If it is not, it will be overwritten when the next new file is created.

c. RECAPITULATION SCREEN. When the preceding data has been completed, a recapitulation screen will appear providing the user with a single screen analysis of the data entered. The user has the option of:

(1) Changing any of the entries (using the procedure discussed below for revising previously created files).

(2) Running the program with the data as entered.

(3) Saving the data file for some future use.

d. REVISING A FILE. The user may revise a file that has been previously created by calling up that file from the block of data file name presented if the CREATE/REVISE CASE command is called. When the highlight bar is located on top of the name of a previously created file, and the ENTER key is pressed, the recapitulation screen for that file is called up. To change the file, respond affirmatively to the question at the bottom of the entry. This will call up a "pull down" menu. At the top of the screen is a list of eight sub-menus and a final item labeled done. The user moves between menus by using the left and right cursor 
keys. As he moves, a sub-menu will appear. To revise an item, locate the highlight bar in the sub-menu on that item and press ENTER. Instructions for revising the item or a sub-menu that allows the user to enter revisions will appear. Brief guidance is provided in the boxes on the bottom of the screen. These are less detailed than the information accompanying the creation of a new file. It is presumed the user has already reviewed those once. When the user finishes making all entries, the cursor moves the highlight on the top line to done and the ENTER key is pressed. This return to the recapitulation screen. At that point, the user has the option of proceeding to run the program, making more changes, or saving the work for a later time.

e. Running a FIRE SIMULATOR case.

The user may call for running a case either directly from the FIRE SIMULATOR menu or as a command when completing the creation or revision of a case file. If he enters directly from the menu, he will have to call up a case file from the screen provided. If cases run directly from the creation/revision program, this phase will be skipped as FIRE SIMULATOR will assume that the case just created or altered is the one to be run.

When the case is to be run, an additional menu appears. This provides the user with the ability to select various run time parameters. They have not been included in the input file as users may elect to run the same case a number of times, changing some of these inputs. Some comments on this initial menu follow.

(1) PRINTER. The default position is off. Press ENTER when the highlight bar is on this item to cause the output to be sent to the printer. If FIRE SIMULATOR cannot find a printer, a message will occur on the screen informing the user that the printer is not online. If the printer is connected and turned on, the screen will return to the menu with the printer turned on. If it is not, the message will stay on the screen until the computer "times out" at which time the menu will reappear with the printer in the off position.

(2) TIME LIMIT. The time limit shown is the maximum time entered for the specified fire. The user may enter a shorter period. If however this indicated time is simulated without flashover occurring, the program will stop for lack of any further information on the fire. After flashover, the user will re-enter fuel data and this time limit will no longer have any impact.

(3) SCREEN OUTPUT. SCREEN OUTPUT controls the intervals at which data will be displayed on the screen and (if the printer is on) print out the data. The default position is off. With screen output in the off position, the screen will show the conditions at the start, at the time of operation of any heat or smoke detectors, at the time of any warning conditions prescribed by the user, at the time 
of flashover, if it occurs, at the time of ventilation limit if such occurs, and at the time of oxygen starvation if such occurs. To add printouts at regular intervals, enter the interval desired in seconds and press the ENTER key.

(4) ASCII FILE. The default condition is ASCII FILE NOT SELECTED. In such case, no ASCII will be created. If one is desired, the user then enters the interval at which data is to be entered. This may be the same or different from the screen output interval.

(5) OUTPUT FILE. FIRE SIMULATOR tracks the total amount of enthaipy and unburned hydrocarbons venting from the burn room through openings into the rest of the building. This data is useful in estimating the impact of the vented products on fire development in an adjacent exposed space. The default name for that file is FIRE.FIR. The user may give a new name to this file. If a new name is not given to this file any previous version of FIRE.FIR will be replaced by the version produced by the current FIRE SIMULATOR run. The output file records the data at 5 second intervals through the run.

(6) APPEND. This command will appear only if there already exists an ASCII file having the same name as that specified for the ASCII file in the case data file. The default position for this is off. If ASCII file is selected and the append function is off, the previous file will be erased and replaced by the one created by this run. If append is turned on, the data sent to the ASCII file will be appended to the previous ASCII file. The APPEND feature is useful when the user wishes to make parametric studies.

(7) DONE. When the cursor is moved to this position and the ENTER key is pressed, the program will operate, presenting output data on the screen and sending it to the printer and/or files as specified.

f. Running FIRE SIMULATOR after flashover.

If smoke temperature as calculated by FIRE SIMULATOR does not reach the level specified as indicating flashover, FIRE SIMULATOR will continue to run until the specified time has elapsed, the maximum time entered for fuel in the fire case file has terminated, conditions indicate that the fire is probably smothering itself, or the program fails to converge.

Except in the case of non-convergence where the user is given the option to continue, all of the above items terminate the program. If flashover occurs, the program stops and the user is given options to change the ventilation conditions in the space and certain fire parameters. The user is also required to enter new data on combustible surfaces. After flashover, FIRE SIMULATOR uses the data to estimate the rate of heat release. Any previously entered fire will be ignored by FIRE SIMULATOR whether or not the time described by that input has expired. If a user wishes to prescribe post-flashover rate of heat release in specifically entered energy terms, the case file should be altered to change the 
flashover temperature to an extraordinarily high level (say $3,000^{\circ} \mathrm{F}$ ) and to enter a time determined halt at any moment the user wishes to have the vent openings changed. Most of the entries are self explanatory.

(1) FUEL QUANTITY DATA. This entry appears as a menu. Specific instructions for each entry appear in the box at the bottom of the screen. The instructions change each time the highlight bar is moved from item to item. When an entry value is made for total horizontal exposed surface, that value will be repeated in the several other entries for exposed surfaces. Similarly, when the first value is entered for total vertical exposed surfaces, it will be repeated in all of the other vertical surfaces. This is done to avoid the necessity of filling out all of the items in those situations where all of the material has a thickness in excess of one inch. In those situations where varying thicknesses are involved, however, the user needs to make specific entries at each level.

g. FAILURE TO CONVERGE. The heart of both FIRE SIMULATOR and ASETBX is a pair of differential equations. The simultaneous solution of these equations uses an approximation approach. The approach is tested to determine if the differential range on both temperature change and change in smoke level converge to within a half a degree variance in temperature and approximately a tenth of an inch in smoke level. If this accuracy is not attained, the calculation is repeated with the new approximation for up to three hundred attempts. If at the end of three hundred attempts the values are separated by more than the allowable range, the program stops and the screen displays a warning reading "SOLUTION DID NOT CONVERGE" and gives the time of non-convergence. It also prints out the report of the environment at that time and presents the user with the prompt "DO YOU WANT TO CONTINUE TO TRY TO EXECUTE THIS RUN $(Y / N) . "$ While this question appears to have only two responses, yes and no, there is actually a third response available. The responses are as follows:

(1) If the user enters $\mathrm{N}$ for no, the program will stop and the user can review the graphs or other production to that point.

(2) If the user answers $Y$ for yes, the program will use the last estimate as the working value and try once more for convergence in the next second of simulation. If it again fails to converge, the message will reappear and the same options will be repeated.

(3) If the user enters $\mathrm{R}$ for repeat, the program will execute and if fire simulation fails to converge, will repeat the message on the screen recording at each step the second of the time at which convergence did not take place but will no longer stop.

Failure to converge is normally due to a sudden change in rate of energy release, smoke temperature, or smoke level. These conditions most often occur at a point of sudden change in the fire such as the opening or closing of a door, post-flashover increase 
in rate of heat release, or precipitous change entered by the user in the fire data file.

While no firm advice can be given on the full impact of continuing after the program has failed to converge, the author's experience indicates that reasonable approximation is still capable if the program starts to converge again after a brief period of time (say less than 5 second). Conversely, if the failure to converge continues beyond that period of time, the system will probably not converge again and even if it does, it is likely that the answers will have diverged too far to be reasonable estimates. Where such occurs, convergence can sometimes be achieved by modest reduction in one or more of the input values related to rate of heat release or size of ventilation opening.

\section{REFERENCES}

1. Cooper, L. Y., and Stroup, D. W.; Calculating Available Safe Egress Time from Fires; Report NBSIR 82-2587; National Institute of Standards and Technology (formerly National Bureau of Standards); 1982 Gaithersburg, MD

2. Life Safety Code; NFPA Standard 101-1985; National Fire Protection Association; Quincy, MA; 1985

3. Quintiere, J. G. and Harkleroad, M. F.; New Concepts for Measuring Flame Spread Properties; Report NBSIR 84-2943; National Institute of Standards and Technology (formerly National Bureau of Standards); Gaithersburg, MD; 1985 


\begin{tabular}{|c|c|c|}
\hline \multirow{3}{*}{$\begin{array}{l}\text { NIST-114A } \\
\text { (REV. 3-89) }\end{array}$} & \multirow{3}{*}{$\begin{array}{l}\text { U.S. DEPARTMENT OF COMMERCE } \\
\text { NATIONAL INSTITUTE OF STANDARDS AND TECHNOLOGY } \\
\text { BIBLIOGRAPHIC DATA SHEET }\end{array}$} & $\begin{array}{l}\text { 1. PUELCATION OR REPORT NUMBER } \\
\text { NISTIR } 4439\end{array}$ \\
\hline & & 2. PEAFORMINO ORQANIZATION REPORT NUMBEA \\
\hline & & $\begin{array}{l}\text { 3. PUBLCATIONDATE } \\
\text { October } 1990\end{array}$ \\
\hline
\end{tabular}

4. TITLE AND SUBTITLE

FPETOOL User's Guide

5. AUTHOR(S)

Harold E. Nelson

6. PERFORMING ORGANIZATION (IF JOINT OA OTHER THAN NIST, SEE INSTRUCTIONS)

U.S. DEPARTMENT OF COMMERCE

MATIONAL INSTITUTE OF STANDARDS AND TECHNOLOGY

GAITHERSBURG, MD 20899

7. CONTRACT/GAANT NUMBER

GSA/PBS-87-03

8. TYPE OF REPOAT AND PERIOD COVERED

9. SPONSORING ORGANIZATION NAME AND COMPLETE ADDRESS (STREET, CTTY, STATE, ZIP)

U.S. General Services Administration

Public Buildings Service

Washington, DC 20405

10. SUPPLEMENTARY NOTES

DOCUMENT DESCRIBES A COMPUTER PROGRAM; SF-185, FIPS SOFTWARE SUMMARY, IS ATTACHED.

11. ABSTRACT (A 200-WORD OR LESS FACTUAL SUMMARY OF MOST SIONIFICANT INFORMATION. IF DOCUMENT INCLUDES A SIOMIFICANT BIBLOGAAPHY OR UTERATURE SURVEY, MENTION IT HERE.)

FPETOOL is a computerized package of relatively simple engineering equations

and models. FPETOOL consists of a package of engineering tools useful in estimating potential fire hazard and the response of the space and fire protection systems to the developing hazard. To a large extent, user instructions are included as screen messages presented at the time of need by FPETOOL. This document covers information useful to the user, but not included as screen messages. A separate report, FPETOOL, Fire Protection Engineering Tools for Hazard Estimation (NISTIR 4380), also is available.

12. KEY WORDS (6 TO 12 ENTRIES; ALPHABETICAL ORDER; CAPITALIE ONLY PROPER NAMES; AND SEPARATE KEY WORDS BY SEMICOLONS) building fires; computer programs; fire hazard; fire protection; fire safety

FOR OFFICIAL DISTRIBUTION. DO NOT RELEASE TO NATIONAL TECHMICAL INFORMATION SEAVICE (NTIS).

ORDEA FROM SUPEAINTENDENT OF DOCUMENTS, U.S. GOVERMMENT PAINTING OFFICE, WASHINGTON, DC 20402.

ORDER FROM MATIONAL TECHNICAL INFORMATION SERVICE (NTIS), SPRINGFIELD, VA 22161.

14. NUMBER OF PAINTED PAGES

\section{7}

15. PRICE

$\mathrm{A03}$ 
. 


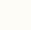

